\title{
Pergolide Associated Cardiac Valvulopathy Based on Ontario Administrative Data
}

\author{
Cindy Zadikoff, Minh Duong-Hua, Kathy Sykora, Connie Marras, \\ Anthony Lang, Paula Rochon
}

\begin{abstract}
Introduction: Pergolide is an ergot derived dopamine agonist that is widely used for the treatment of Parkinson's disease. Studies have found an association between pergolide and valvular heart abnormalities although there is still much to be learned about the clinical significance of the valvular changes, who is at risk, and whether there is duration of exposure effect. Objective: To assess the long term risk of hospital admissions for valvular heart disease (VHD) or congestive heart failure (CHF, a clinically overt outcome of VHD) in new users of pergolide compared to new users of levodopa. The secondary objective was to assess whether there are any characteristics that can predict who is at higher risk of developing this outcome. Design: Retrospective, population-based cohort study. Setting: Ontario, Canada. Subjects: Ontario residents aged 66 and older, newly started on treatment with either pergolide or levodopa. Outcomes: Admission to hospital with the most responsible diagnosis of congestive heart failure or valvular heart disease. Results: The risk for admission for valvular heart disease or congestive heart failure were higher in those with 1-4 years exposure to pergolide compared with no exposure to pergolide (VHD: hazard ratio 2.4, $\mathrm{p}=0.04$; CHF: hazard ratio 1.6, $\mathrm{p}=0.02$ ). No such pattern was found with exposure to levodopa.Conclusion: Our study demonstrates that treatment with pergolide is associated with a higher risk of hospital admission for valvular heart disease or congestive heart failure and that this risk is greater in those with 1-4 years exposure than in those with less exposure. We did not find an increased risk beyond four years.
\end{abstract}

RÉSUMÉ: Valvulopathie associée au pergolide selon des données administratives de l'Ontario. Contexte : Le pergolide est un agoniste de la dopamine qui est dérivé de l'ergot. Il est couramment utilisé dans le traitement de la maladie de Parkinson. Des études ont mis en évidence une association entre le pergolide et des anomalies valvulaires cardiaques. Cependant on ne connaît pas la signification clinique des changements valvulaires, quels patients sont à risque et si la durée d'exposition a un effet. Objectif : Le but de cette étude était d'évaluer le risque à long terme d'hospitalisation pour maladie cardiaque valvulaire (MCV) ou insuffisance cardiaque congestive (ICC, une conséquence clinique de la MCV) chez des patients qui prennent du pergolide depuis peu et chez des patients qui prennent de la lévodopa depuis peu. L'objectif secondaire était d'évaluer s'il existe des caractéristiques qui pourraient prédire qui est à plus haut risque de MCV. Plan d'étude : Il s'agit d'une étude rétrospective de cohorte tirée de la population. Cadre : Cette étude a été effectuée en Ontario, au Canada. Sujets : Nous avons examiné les données de résidents de l'Ontario, âgés de 66 ans et plus, qui prenaient du pergolide ou de la lévodopa depuis peu. Critères d'évaluation : Un diagnostic d'ICC ou de MCV comme motif principal d'hospitalisation. Résultats : Le risque d'admission pour MCV ou ICC était plus élevé chez ceux qui avaient été exposés pendant 1 à 4 ans au pergolide par rapport à ceux qui n'y avaient pas été exposés (MCV; rapport de risques 2,4 p = 0,04; ICC : rapport de risques $1,6 \mathrm{p}=0,02)$, ce qui n'était pas le cas pour la lévodopa. Conclusion : Cette étude démontre que le traitement par le pergolide est associé à un risque plus élevé d'hospitalisation pour MCV ou ICC et que ce risque est plus élevé chez ceux qui y ont été exposés pendant 1 à 4 ans que chez ceux dont la durée d'exposition est moindre. Le risque n'augmentait pas davantage si la durée d'exposition était de plus de 4 ans.

Can. J. Neurol. Sci. 2008; 35: 173-178

Pergolide mesylate is an ergot derived dopamine agonist that is widely used for the management of Parkinson's disease and restless leg syndrome. Valvular heart disease has been described in patients taking other ergot derived agents, such as methylsergide. ${ }^{1-3}$ It was not until 2002 that valvular heart disease in association with pergolide use was documented in three patients. ${ }^{4}$ Since that time, The World Health Organization ${ }^{5}$ and Health Canada ${ }^{6}$ issued warnings about pergolide therapy and the risk of developing cardiac valvulopathy; the drug was voluntarily withdrawn from the US market in 2007.7 The pathophysiology is akin to that found in carcinoid syndrome and the valvulopathy associated with the anorectic drugs, fenfluramine and dexfenfluramine. ${ }^{8}$ In carcinoid heart disease,

From the Morton and Gloria Shulman Movement Disorders Center (CZ, CM, AL), Toronto Western Hospital, Department of Neurology; Institute for Clinical Evaluative Sciences (MDH, KS, PR); Kunin Lunenfeld Applied Research Unit, (KLARU) (PR),

Toronto, Ontario, Canada; Parkinson's Disease and Movement Disorders Center (CZ), Northwestern University, Chicago, USA.

Received July 25, 2007. Final Revisions Submitted November 8, 2007. Reprint requests to: Cindy Zadikoff, Northwestern University, 710 N Lake Shore Dr Ste 1104 , Chicago, IL, 60611, USA. 
serotonin excess is thought to correlate with the development of valvular lesions..$^{8,9}$ Although the dopamine agonists are used for their dopaminergic properties, they have been shown to have a variable affinity for the 5-HT2B serotonin receptor, and the ergotamine derived agonists, pergolide and cabergoline, have the highest affinity for this serotonin receptor. ${ }^{10}$ Therefore, there is a biologically plausible association between pergolide and cardiac valvulopathy. Numerous studies have assessed the risk of developing cardiac valvulopathy in association with pergolide use. ${ }^{11-15}$ Most of these studies have been limited by relatively small sample sizes, variable methods to assess valvular disease on echocardiogram, and lack of systematic follow-up or clinical correlation. ${ }^{16}$ Furthermore, while some studies have found a risk of valvular disease as high as $30 \%{ }^{17}$ with a direct relation between dose and duration of exposure and valvular changes, ${ }^{12,13,15}$ other studies have found much lower risks ${ }^{18}$ without a clear dose or duration effect. ${ }^{14}$ Finally, by using echocardiographic outcomes, most studies fail to provide information about the clinical impact of the valvular changes. Therefore, there is still much to be learned about the nature of the cardiac risk associated with pergolide use, including the exact mechanism and frequency of pergolide induced valvulopathy. We add to the current state of knowledge by performing a population-based study of older adults with Parkinson's disease, using administrative health care data, to determine whether there is an association between pergolide use and hospitalizations for cardiac valvulopathy. By using this outcome measure our study provides insight into the clinical impact of pergolide-associated valvular heart disease.

\section{MeTHODS}

\section{Databases}

Four databases in the Canadian province of Ontario were linked using common, encrypted unique identifiers. The linked databases included computerized pharmacy records of the Ontario Drug Benefit (ODB) program, which records prescription drugs dispensed to all Ontario residents 65 years or older. Acute-care hospitalization records were obtained from the Canadian Institute for Health Information (CIHI) Discharge Abstract Database, which uses the International Classification of Diseases, Ninth (ICD-9) and Tenth (ICD-10) revisions nomenclature to provide detailed diagnostic records for all hospital admissions. The Ontario Health Insurance Plan (OHIP) records provides physician billing information for inpatient and outpatient services, and the Registered Persons Database (RPDB) contains basic demographic information and vital statistics for each patient.

\section{Cohort definition}

A set of adults aged 66 years and older who were new users of either pergolide or levodopa was identified from claims through the ODB from January 1, 1994 to December 31, 2000. To restrict our cohort to new users, we looked back one year from the first date of dispensation to ensure that subjects had not previously received any prescriptions for pergolide or levodopa. Subjects were excluded if 1) they had a prior (defined as a prescription any time in the previous year) or concurrent prescription for any other ergotamine derived drug, dopamine agonist, or anorectic drug, such as fenfluramine or dexfenfluramine or 2) in the previous three years, they had a diagnosis of rheumatic heart disease, congestive heart failure, or valvular replacement or major cardiac surgery (a description of the codes used is provided in the Appendix) so as not to confound the analysis by including those with preexistence of the outcomes in question.

After applying the above criteria, we then included only those subjects alive and event free for five years after their first pergolide/levodopa claim. This was done to look at longer term effects of the drug and avoid a "healthy survivor effect." For example, subjects predisposed to cardiac valvulopathy might develop the outcome (and therefore be censored from further observation) after only a short exposure to the drug, in which case, only patients with long exposure to the drug who had not yet reached the outcome would be retained in the cohort. This could lead to an erroneous conclusion that long term exposure to drugs is actually protective. Because excluding subjects if they experienced either CHF or VHD during the first five years would

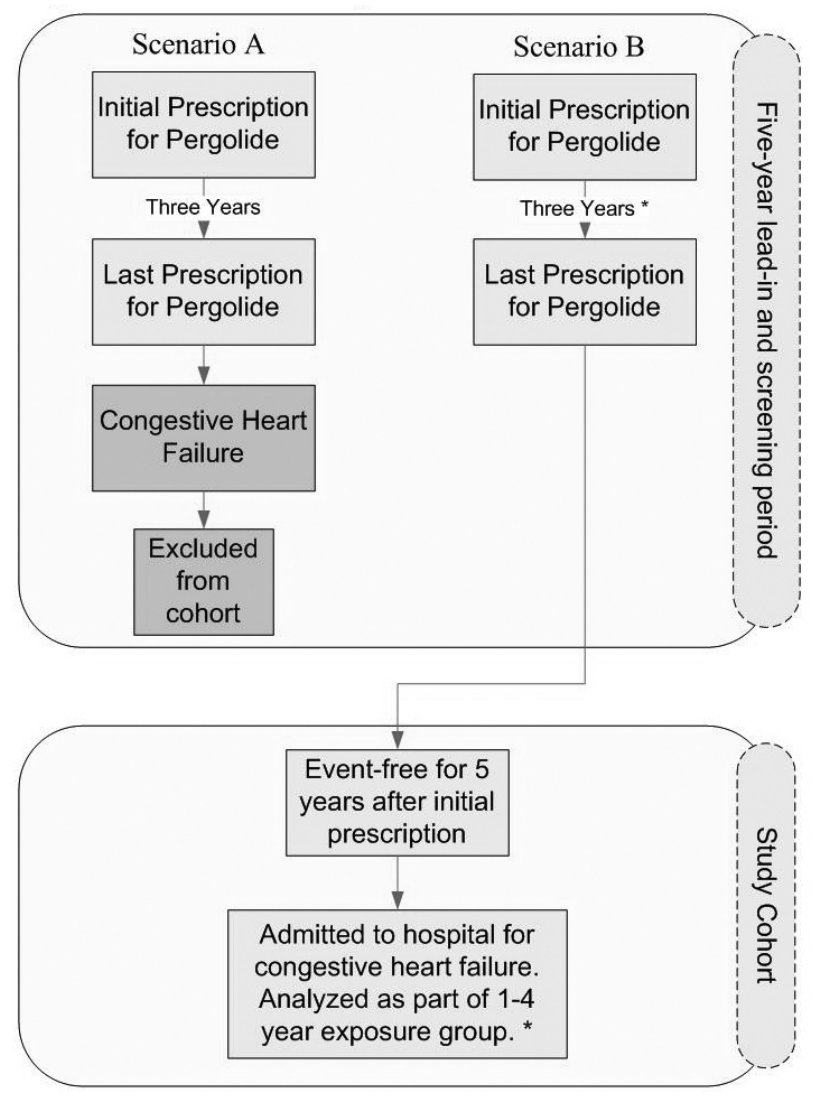

Figure 1: Scenarios for being included or excluded in the cohort. *If received drug $<1$ year, analyzed as $<1$ year. If received drug $1-4$ years, analyzed as 1-4 years. If received drug $>4$ years, analyzed as $>4$ years. 


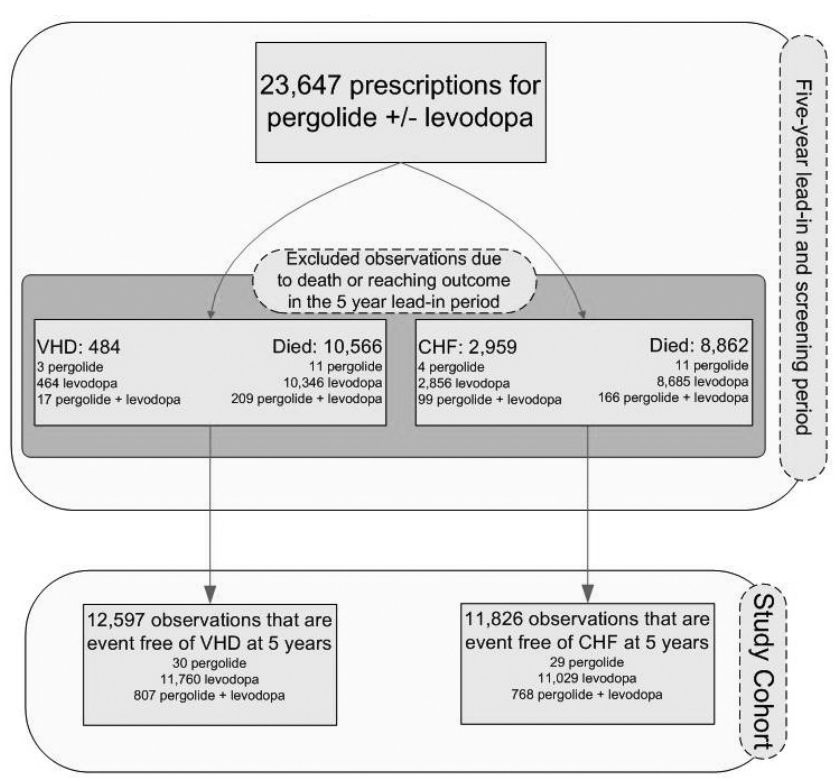

Figure 2: Subject flow diagram

have resulted in a much smaller cohort, we chose to separate these two outcomes into two separate cohorts (ie subjects who survived free of $\mathrm{CHF}$ for five years and subjects who survived free of VHD for five years. Because a subject could be free of both outcomes at five years, there are some subjects $(n=776)$ who were included in both cohorts). Next, patients were classified into four different groups based on their exposure to pergolide and levodopa during those first five years: no exposure, less than one year exposure, 1-4 years exposure, and $>4$ years exposure. Exposure to each drug was computed as the time from the first claim for that drug until 14 days past the last claim. If the last claim occurred after the five-year mark, or less than 14 days prior to the five-year mark, the subject was considered exposed to that drug until the end of the five-year period. Patients were observed starting five years after their initial use of the first study drug until they died, reached the outcome event, or the follow up period ended (Dec 31, 2005). Note that since we considered two different outcome events (VHD and CHF), the set of subjects "event-free at five years" was slightly different for the two. Figure 1 provides different scenarios explaining how subjects might be included or excluded from the cohort.

\section{Outcomes and Potential Confounders}

The primary outcome was clinically overt sequelae of cardiac valvulopathy as defined by admission to hospital with the most responsible diagnosis of valvular heart disease or congestive heart failure (Appendix). Because the accuracy of coding for valvular heart disease using these databases has not been systematically studied, it is unknown how well or how often this diagnosis is reflected in medical coding. Therefore, congestive heart failure was chosen as an outcome of interest because it is the most likely clinically overt outcome of valvulopathy and has been validated using these databases. ${ }^{19}$ Most responsible diagnosis refers to the condition responsible for the longest length of stay. It is a term used by trained abstractors who complete data collection for the Canadian Institute for Health Information to distinguish between the main reason for admission and comorbid conditions. The coding accuracy of drug claims in the ODB database is excellent; an error rate of only $0.7 \%$ has been documented..$^{20}$ The covariates in our models are factors that might influence the development of cardiac valvular disease or congestive heart failure, including age, gender, and other cardiac comorbidities, such as hypertension or cardiomyopathy (as defined in previous studies). ${ }^{21}$ As an overall

Table 1a: Baseline characteristics by drug group-Cohort free of valvular heart disease at five years

\begin{tabular}{l|c|c|c}
\hline & $\begin{array}{c}\text { Pergolide } \\
\text { Only } \\
(\mathrm{n}=30)\end{array}$ & $\begin{array}{c}\text { Levodopa } \\
\text { Only } \\
(\mathrm{n}=11760)\end{array}$ & $\begin{array}{c}\text { Pergolide and } \\
\text { Levodopa } \\
(\mathrm{n}=807)\end{array}$ \\
\hline $\begin{array}{l}\text { Age (years) } \\
\text { Median (range) }\end{array}$ & $74(66,105)$ & $75(66-99)$ & $72(66-91)$ \\
\hline $\begin{array}{l}\text { Number of DINs }{ }^{\text {a }} \\
\text { (Range) }\end{array}$ & $10(1-38)$ & $8(0-56)$ & $6(0-34)$ \\
\hline $\begin{array}{l}\text { Baseline Charlson Index Score } \\
\text { Median (Range) }\end{array}$ & $0(0-1)$ & $0(0-9)$ & $0(0-6)$ \\
\hline $\begin{array}{l}\text { Sex M:F } \\
(\% M)\end{array}$ & $18: 12$ & $5352: 6408$ & $425: 382$ \\
$(60)$ & $(45.5)$ & $(52.7)$ \\
\hline $\begin{array}{l}\text { Heart Failure Comorbidities } \\
\text { Y(\%) }\end{array}$ & $<5(10)$ & $1549(13.2)$ & $68(8.6)$ \\
\hline
\end{tabular}

Table 1b: Baseline characteristics by drug group-Cohort free of congestive heart failure at five years

\begin{tabular}{l|c|c|c}
\hline & $\begin{array}{c}\text { Pergolide } \\
\text { Only } \\
(\mathrm{n}=29)\end{array}$ & $\begin{array}{c}\text { Levodopa } \\
\text { Only } \\
(\mathrm{n}=11029)\end{array}$ & $\begin{array}{c}\text { Pergolide and } \\
\text { Levodopa } \\
(\mathrm{n}=768)\end{array}$ \\
\hline $\begin{array}{l}\text { Age (years) } \\
\text { Median (range) }\end{array}$ & $72(66-84)$ & $75(66-99)$ & $72(66-91)$ \\
\hline $\begin{array}{l}\text { Number of DINs } \\
\text { Median (Range) }\end{array}$ & $10(1-38)$ & $8(0-56)$ & $6(0-34)$ \\
\hline $\begin{array}{l}\text { Baseline Charlson Index Score } \\
\text { Median (Range) }\end{array}$ & $0(0-1)$ & $0(0-9)$ & $0(0-6)$ \\
\hline $\begin{array}{l}\text { Sex M:F } \\
(\% \mathrm{M})\end{array}$ & $17: 12$ & $5021: 6008$ & $406: 362$ \\
\hline $\begin{array}{l}\text { Heart Failure Comorbidities } \\
\text { Y(\%) }\end{array}$ & $(58.6)$ & $(45.5)$ & $(52.9)$ \\
\hline
\end{tabular}

${ }^{\text {a }}$ DINs - Drug Identification Number 
measure of comorbidity, we used the number of distinct drugs (DINs) dispensed in the year prior to cohort entry ${ }^{22}$ as well as the Charlson comorbidity index..$^{23}$

\section{Statistical Analysis}

Time -to-event analyses for the primary outcomes (CHF or VHD) were conducted using the Cox proportional hazards model. Separate analyses were run for each outcome using the four categories of exposure described earlier. The cohort that survived VHD-free for five years was analyzed using VHD as an outcome, and the cohort that survived CHF-free for five years was analyzed using CHF as the outcome. All analyses controlled for age, sex, and comoribidies (as described above). All reported $\mathrm{P}$ values are two-tailed, with significance level of 0.05 , and $95 \%$ confidence intervals (CIs) were calculated for all hazard rate ratios. All analyses were performed with SAS for UNIX, version 9 (SAS Institute, Inc., Cary, NC). This study was approved by the ethics review board of Sunnybrook and Women's College Health Sciences Centre, Toronto, Ontario.

\section{RESULTS}

The initial cohort consisted of 23,647 individuals (Figure 2). Of these 12,597 (53.3\%) survived VHD-free after five years, and $11,826(50.0 \%)$ survived CHF-free after five years. In each of these cohorts, $0.2 \%$ was exposed only to pergolide, $93 \%$ were exposed only to levodopa, and the remaining $6 \%$ were exposed to both drugs. The baseline characteristics of the cohort by outcome (those who were VHD-free after five years and those who were CHF-free after five years) are listed in Table 1.

Over a five-year-period, 12,597 subjects survived free of valvular heart disease and were included in the analysis using valvular heart disease as the outcome (30 subjects on pergolide, 11760 on levodopa, and 807 on both). Mean follow-up time (including endpoints of death, hospitalization for VHD or Dec 31,2005 ) was 2.43 years with maximum follow-up being seven years. There were a total of 141 events: none in the pergolide only group, $129(1.1 \%)$ in the levodopa only group, and 12 $(1.5 \%)$ in those taking both drugs. Two patients died during admission for valvular heart disease. In those with one-four years exposure to pergolide there was a higher risk of being admitted for valvular heart disease (hazard ratio (HR) 2.4, 95\% CI 1.0, $5.4, \mathrm{p}=0.04)$ compared to those with no exposure. No similar pattern was found for levodopa only exposure. Because there were no events in the pergolide only group, the reference groups are different for levodopa and pergolide groups. Male gender (HR 1.3, 95\% CI 1.0, 2.0, p= .06) was also associated with a higher risk of reaching the outcome. (Table 2a)

Over a five year period, 11,826 subjects survived free of congestive heart failure and were included in the analysis using congestive heart failure as the outcome (29 subjects on pergolide, 11029 on levodopa, and 768 on both). Mean followup time (including endpoints of death, hospitalization for $\mathrm{CHF}$ or Dec 31,2005$)$ was 2.45 years with maximum follow-up being 7 years. There were a total of 813 events; 3 in the pergolide only group (10.3\%) 752 in the levodopa only group (6.8\%), and 58 (7.6\%) in those taking both drugs. As when valvular heart disease was used as an outcome, in those with one-four years exposure to pergolide there was a higher risk of being admitted with congestive heart failure compared to no exposure, (HR $1.6,95 \%$ CI 1.1, 2.5, $\mathrm{p}=0.02$ ). No similar pattern was found for levodopa exposure. Male gender, the presence of other cardiac comorbidities, age, a higher Charlson index score, and a higher number of DINs were also associated with a higher risk of reaching the outcome, although the hazard ratios for the latter three were minimally elevated above 1 . (Table $2 \mathrm{~b}$ )

Table 2a: COX regression model of valvular heart disease with any pergolide and levodopa exposure

\begin{tabular}{|c|c|c|c|c|}
\hline Variable & $\begin{array}{c}\text { Hazard } \\
\text { ratio }\end{array}$ & $\begin{array}{c}95 \% \\
\text { Lower CI }\end{array}$ & $\begin{array}{c}95 \% \\
\text { Upper CI }\end{array}$ & P-value \\
\hline \multicolumn{5}{|l|}{ Pergolide Exposure (n) } \\
\hline no exposure (reference) $(11,760)$ & 1.00 & & & \\
\hline < 1 year $(398)$ & 0.67 & 0.21 & 2.09 & 0.48 \\
\hline $1-4$ years $(258)$ & 2.35 & 1.02 & 5.41 & 0.04 \\
\hline$>4$ years $(181)$ & 1.45 & 0.46 & 4.60 & 0.53 \\
\hline \multicolumn{5}{|l|}{ Levodopa Exposure (n) } \\
\hline$<1$ year (reference) $(3,310)$ & 1.00 & & & \\
\hline $1-4$ years $(1356)$ & 0.96 & 0.54 & 1.71 & 0.89 \\
\hline$>4$ years $(7901)$ & 0.84 & 0.57 & 1.22 & 0.35 \\
\hline Age & 1.0 & 1.0 & 1.0 & .38 \\
\hline Gender (M) & 1.3 & 1.0 & 2.0 & 0.06 \\
\hline Charlson Index Score & 1.1 & 0.9 & 1.4 & 0.26 \\
\hline Co-morbidity of Heart Failure & 1.3 & .8 & 2.1 & 0.28 \\
\hline Number of DINs ${ }^{a}$ & 1.0 & 1.0 & 1.1 & 0.02 \\
\hline
\end{tabular}

Table 2b: COX regression model of congestive heart failure with any pergolide and levodopa exposure

\begin{tabular}{|c|c|c|c|c|}
\hline Variable & $\begin{array}{l}\text { Hazard } \\
\text { ratio }\end{array}$ & $\begin{array}{c}95 \% \\
\text { Lower CI }\end{array}$ & $\begin{array}{c}95 \% \\
\text { Upper CI }\end{array}$ & P-value \\
\hline \multicolumn{5}{|l|}{ Pergolide exposure (n) } \\
\hline $\begin{array}{l}\text { No exposure (reference) } \\
(11,029)\end{array}$ & 1.00 & & & \\
\hline$<1$ year $(380)$ & 0.88 & 0.58 & 1.33 & 0.54 \\
\hline $1-4$ years $(250)$ & 1.65 & 1.09 & 2.48 & 0.02 \\
\hline$>4$ years $(167)$ & 1.1 & 0.62 & 1.96 & 0.76 \\
\hline \multicolumn{5}{|l|}{ Levodopa Exposure (n) } \\
\hline No exposure (reference) (29) & 1.00 & & & \\
\hline$<1$ year $(3,104)$ & 0.45 & 0.14 & 1.49 & 0.19 \\
\hline $1-4$ years $(1248)$ & 0.52 & 0.15 & 1.72 & 0.28 \\
\hline$>4$ years $(7445)$ & 0.47 & 0.14 & 1.55 & 0.21 \\
\hline Age & 1.06 & 1.05 & 1.07 & $<0.0001$ \\
\hline Gender (M) & 1.27 & 1.1 & 1.46 & 0.0009 \\
\hline Charlson Index Score & 1.13 & 1.04 & 1.23 & .0033 \\
\hline Co-morbidity of Heart Failure & 1.20 & 0.98 & 1.47 & 0.08 \\
\hline Number of DINs ${ }^{a}$ & 1.03 & 1.02 & 1.04 & $<0.0001$ \\
\hline
\end{tabular}

${ }^{\text {a }}$ DINs - Drug Identification Number 


\section{Discussion}

Our study confirms that users of pergolide have a higher risk of clinically overt sequelae of valvular heart disease than nonusers. Our study adds to previous investigations by demonstrating an increased risk of hospital admissions for valvular heart disease or congestive heart failure in these patients, indicating that the valvular changes related to pergolide use can be clinically important. Furthermore, the risk appears to increase with duration of exposure up to a point (four years based on the exposure categories used in this study). Because this study is population based and involves a large cohort it adds an important contribution to the literature because it allows one to quantify this risk for the general population better than studies using selected samples. While the majority of patients were on levodopa, there were still over 800 subjects exposed to pergolide, which is the largest sample available in the literature studying this question. The results of this analysis are in keeping with the only other population based study, which found that pergolide and cabergoline (another ergot-derived dopamine agonist) were associated with an increased risk of newly diagnosed cardiac valve regurgitation. ${ }^{24}$

Our study also assessed whether various medical and demographic risk factors might influence who is at higher risk of developing pergolide induced valvulopathy - something that has not been addressed in previous studies. This knowledge would help guide clinicians in deciding who is at higher risk, and thus, in whom the drug should be avoided. Older age, male gender, higher number of prescriptions for any medication (as a surrogate marker of overall health status), and cardiac comorbidities were all found to be significant ( $\mathrm{p}$ values $<.05$ ). However, the associated hazard ratios were quite small suggesting a minimal increased risk associated with each of these factors.

\section{LIMITATIONS}

Our study has a number of limitations that must be acknowledged. First, because we chose to include people only if they remained event free for five years, we ignored early effects of the drug. It is also possible that people in the longer exposure group who might be prone to valvular heart disease already had the outcome during the first five years, and therefore, were eliminated from the cohort. Thus, it might falsely appear that longer exposure to the drug is actually protective. We tried to avoid this "healthy survivor effect," by requiring that all patients remain event free for five years (regardless of their exposure to the drug) in order to be included in the cohort. However, this might explain why we did not see an increased hazard ratio in the $>4$ year exposure group. It is also possible that we did not find increased hazard ratio in the $>4$ year exposure group due to lack of power (fewer subjects in that group). Finally, because this study used an administrative database with minimal clinical detail, a stringent outcome (admission to hospital) was required. By using admission to hospital as an outcome, milder cases of pergolide induced cardiac valvulopathy almost certainly were missed. However, the group we identified using these methods represents those patients of greatest interest. Some degree of valvular regurgitation can be found in a large majority of the general population, ${ }^{25}$ and therefore, it is not clear how clinically relevant a similar finding is in a patient on pergolide. By restricting the outcome to those with admission to hospital, we attempted to determine how frequently pergolide valvulopathy results in serious cardiac morbidity, although it is certainly possible that some patients with clinically relevant disease might have been managed as an outpatient, and thus, would not have been included in this cohort.

\section{Conclusion}

Our study confirms that treatment with pergolide is associated with a higher risk of admission to hospital for valvular heart disease or congestive heart failure and that this risk is greater in those with one-four years exposure than in those with less exposure. We did not find an increased risk beyond four years of exposure.

\section{ACKNOWLEDGMENTS}

Cindy Zadikoff was funded by an AAN foundation clinical fellowship award. Paula Rochon is supported by a CIHR Investigator Award. This work was supported by a CIHR Chronic Disease New Emerging Team program (NET - 54010). The NET program receives joint sponsorship from the Canadian Diabetes Association, the Kidney Foundation of Canada, the Heart and Stroke Foundation of Canada and the CIHR Institutes of Nutrition, Metabolism \& Diabetes and Circulatory \& Respiratory Health.

\section{REFERENCES}

1. Hendrikx M, Van Dorpe J, Flameng W, Daenen W. Aortic and mitral valve disease induced by ergotamine therapy for migraine: a case report and review of the literature. J Heart Valve Dis. 1996; 5:235-7.

2. Redfield MM, Nicholson WJ, Edwards WD, Tajik AJ. Valve disease associated with ergot alkaloid use: echocardiographic and pathologic correlations. Ann Intern Med. 1992; 117:50-2.

3. Flaherty KR, Bates JR. Mitral regurgitation caused by chronic ergotamine use. Am Heart J. 1996; 131:603-6.

4. Pritchett AM, Morrison JF, Edwards WD, Schaff HV, Connolly HM, Espinosa RE. Valvular heart disease in patients taking pergolide. Mayo Clin Proc. 2002; 77:1280-6.

5. Pergolide mesilate: strengthened warning. WHO Drug Information v17i1, 37. 2003

6. Health Canada Warning. http://www.hc-sc.gc.ca/dhp-mps/medeff/ advisories-avis/prof/2004/shire_permax_hpc-cps_e.html. 2-172004.

7. Pergolide pulled from market. 2007. http://www.fda.gov/cder/ drug/advisory/pergolide.htm

8. Connolly HM, Crary JL, McGoon MD, Hensrud DD, Edwards BS, Edwards WD, et al. Valvular heart disease associated with fenfluramine-phentermine. N Engl J Med. 1997; 337:581-8.

9. Robiolio PA, Rigolin VH, Wilson JS, Harrison JK, Sanders LL, Bashore TM, et al. Carcinoid heart disease. Correlation of high serotonin levels with valvular abnormalities detected by cardiac catheterization and echocardiography. Circulation. 1995; 92:790-5.

10. Millan MJ, Maiofiss L, Cussac D, Audinot V, Boutin JA, NewmanTancredi A. Differential actions of antiparkinson agents at multiple classes of monoaminergic receptor. I. A multivariate analysis of the binding profiles of 14 drugs at 21 native and cloned human receptor subtypes. J Pharmacol Exp Ther. 2002; 303:791-804

11. Van Camp G, Flamez A, Cosyns B, Goldstein J, Perdaens C, Schoors D. Heart valvular disease in patients with Parkinson's disease treated with high-dose pergolide. Neurology. 2003; 61:859-61. 
12. Zanettini R, Antonini A, Gatto G, Gentile R, Tesei S, Pezzoli G. Valvular heart disease and the use of dopamine agonists for Parkinson's disease. N Engl J Med. 2007; 356:39-46.

13. Baseman DG, O'Suilleabhain PE, Reimold SC, Laskar SR, Baseman JG, Dewey RB, Jr. Pergolide use in Parkinson disease is associated with cardiac valve regurgitation. Neurology. 2004; 63:301-4.

14. Peralta C, Wolf E, Alber H, Seppi K, Muller S, Bosch S, et al. Valvular heart disease in Parkinson's disease vs. controls: An echocardiographic study. Mov Disord. 2006; 21:1109-13.

15. Waller EA, Kaplan J, Heckman MG. Valvular heart disease in patients taking pergolide. Mayo Clin Proc. 2005; 80:1016-20.

16. Zadikoff $\mathrm{C}$, Rochon P, Lang A. Cardiac valvulopathy associated with pergolide use. Can J Neurol Sci. 2006; 33:27-33.

17. Van Camp G, Flamez A, Cosyns B, Weytjens C, Muyldermans L, Van Zandijcke M, et al. Treatment of Parkinson's disease with pergolide and relation to restrictive valvular heart disease. Lancet. 2004; 363:1179-83.

18. Kim JY, Chung EJ, Park SW, Lee WY. Valvular heart disease in Parkinson's disease treated with ergot derivative dopamine agonists. Mov Disord. 2006; 21:1261-4.

19. Lee DS, Donovan L, Austin PC, Rouleau JL, Liu PP, Naimark D, et al. Comparison of coding of heart failure and comorbidities in administrative and clinical data for use in outcomes research. Med Care. 2005; 43:182-8

20. Levy AR, O'Brien BJ, Sellors C, Grootendorst P, Willison D. Coding accuracy of administrative drug claims in the Ontario Drug Benefit database. Can J Clin Pharmacol. 2003; 10:67-71.

21. Barker WH, Mullooly JP, Getchell W. Changing incidence and survival for heart failure in a well-defined older population, 1970-1974 and 1990-1994. Circulation. 2006; 113:799-805.

22. Schneeweiss S, Seeger JD, Maclure M, Wang PS, Avorn J, Glynn RJ. Performance of comorbidity scores to control for confounding in epidemiologic studies using claims data. Am J Epidemiol. 2001; 154:854-64.

23. Charlson ME, Pompei P, Ales KL, MacKenzie CR. A new method of classifying prognostic comorbidity in longitudinal studies: development and validation. J Chronic Dis. 1987; 40:373-83.

24. Schade R, Andersohn F, Suissa S, Haverkamp W, Garbe E. Dopamine agonists and the risk of cardiac-valve regurgitation. $\mathrm{N}$ Engl J Med. 2007; 356:29-38.

25. Singh JP, Evans JC, Levy D, Larson MG, Freed LA, Fuller DL, et al. Prevalence and clinical determinants of mitral, tricuspid, and aortic regurgitation (the Framingham Heart Study). Am J Cardiol. 1999; 83:897-902.
Appendix: Codes used for exclusion criteria and outcome measures

\begin{tabular}{|c|c|}
\hline \multicolumn{2}{|c|}{ Exclusion Criteria } \\
\hline \multicolumn{2}{|c|}{ Canadian Institute for Health Information Discharge Abstract Database: } \\
\hline Rheumatic heart disease & $\begin{array}{l}\text { ICD-9: 391, 392, 394, 395, 397, 398, } 391 \\
\text { ICD-10: I01, I02, I05, I06, I07 }\end{array}$ \\
\hline Congestive heart failure & $\begin{array}{l}\text { ICD-9: } 415,428 \\
\text { ICD-10: } 150\end{array}$ \\
\hline $\begin{array}{l}\text { Valvular replacement/major } \\
\text { cardiac surgery }\end{array}$ & $\begin{array}{l}\text { ICD-9: V433 } \\
\text { ICD-10 Z95 } \\
\text { CCP: } 47 \\
\text { CCI: } 1 \text { HS } 80,1 \text { HS90, 1HT80, 1Ht89, 1HT90, } \\
\text { 1HU } 80,1 \text { HU90, 1HV80, 1HV90 }\end{array}$ \\
\hline Ontario Drug Benefit Plan & $\begin{array}{l}\text { Any use of other ergotamine derived drug, } \\
\text { dopamine agonist or anorectic drug }\end{array}$ \\
\hline \multicolumn{2}{|c|}{ Outcome Measures } \\
\hline \multicolumn{2}{|c|}{ Canadian Institute for Health Information Discharge Abstract Database: } \\
\hline $\begin{array}{l}\text { Valvular heart disease } \\
\text { Valvular repair/replacement }\end{array}$ & $\begin{array}{l}\text { ICD-9: } 394,396,397,424 \\
\text { ICD-10: I08, I34, I36, I35 I37 } \\
\text { CCP: } 47 \\
\text { CCI: } 1 \text { HS } 80 \text {, 1HS90, 1HU80, 1HU90, 1HV80 } \\
\text { 1HV90 }\end{array}$ \\
\hline Congestive heart failure & $\begin{array}{l}\text { ICD-9: } 415,428 \\
\text { ICD-10: I50 }\end{array}$ \\
\hline
\end{tabular}

